\title{
Clinical surgery-oriented subject librarian services in medical colleges and schools ${ }^{\dagger}$
}

Review article

Qiang $\mathrm{He}^{*}$

Library of Shanxi Medical University, Taiyuan, Shanxi 030001, China

Received: 26 December 2017; Accepted: 15 March 2018; Published: 20 December 2018

\begin{abstract}
Regarding subject librarian services for clinical studies, researchers outside China have been focusing on subject service performance, evidence-based medicine, and comprehensive consulting services. In contrast, Chinese researchers have concentrated on service systems and methods but have not established mature systems and methods for clinical surgery-oriented services. Therefore, subject librarians in medical schools should become involved in clinical research and expand their perspective on medical library research. In addition, they should collaborate with clinicians to improve the overall level of research in hospitals while increasing the impact of subject librarian services in medical colleges and schools.
\end{abstract}

Keywords: subject librarian • surgery • medical schools • evidence-based medicine • bibliometrics $\bullet$ review

(C) Shanxi Medical Periodical Press.

\section{Introduction}

In recent years, the involvement of subject librarians in clinical medicine and the development of related clinical disciplines have become a popular topic in library and information science. In the context of the big data environment, many subject librarians are taking the initiative to integrate themselves in the medical environment and collaborating closely with medical workers. Specialized subject librarians have eased a bottleneck in the medical field by addressing the problems faced by medical personnel. These efforts have increased the value of the librarian team. ${ }^{1}$ This type of higher-level subject librarian is referred to as an "embedded librarian". 2 Such librarians are increasingly in service.

With the modernization of hospital construction and medical disciplines in China, medical subject librarians

'This study was supported by 2016 Shanxi Medical University Youth Fund (No.02201640).

* Corresponding author.

E-mail: hq@sxmu.edu.cn (Q. He).

¿ Open Access. ๑ 2018 Qiang He, published by Sciendo. (๕) BY-Nc-ND Attribution NonCommercial-NoDerivatives 4.0 License. are receiving more demand for their expertise. Overall, the development of hospital information services in China is uneven. First-class tertiary hospitals in the developed regions enjoy the advantages of concentrated manpower and information resources. However, hospitals in other regions are significantly lagging behind in information services. Libraries in medical universities must seize the opportunity created by the subject librarian system and strive to create a new service mode. Their success would have a win-win effect on the development of library information science and innovative medical technology.

\section{Theoretical basis}

Medical science is systemic and complex. Substantial time and effort are required to master a single branch of medicine. Thus, the specialized medical services that a single subject librarian can provide are limited. Medical science can be divided into several level 1 disciplines, e.g., clinical medicine, preventive medicine, or 
pharmacy. However, it is impossible for an individual subject librarian to be familiar with every medical discipline. Therefore, it is necessary to establish an efficient subject librarian team, ${ }^{3}$ whose members work together to serve a medical discipline. For example, clinical medicine is a level 1 discipline and can be divided into 18 level 2 disciplines, including major areas such as surgery, internal medicine, nursing, and oncology. ${ }^{4}$ Thus, to improve research efficiency, a subject librarian should concentrate on one level 2 subject.

To provide another example, according to the Chinese Library Classification system, Category $\mathrm{R}$ includes Medicine and Public Health, in which R6 Surgical Science is a typical representative category that includes various subcategories, such as R61 Surgical Technique, R62 Plastic Surgery, R63 Surgical Infections, R64 Trauma Surgery, and R65 Special Topics in Surgery. ${ }^{5}$ In addition, because the scope of modern surgery is gradually expanding, surgeons today are not only required to perform surgery but also must conduct investigations on basic theories related to surgery, e.g., etiology, pathology, pathogenesis, diagnosis, and prevention. The traditional surgeon who was only interested in surgical skills but not in in-depth pathological studies is increasingly less common in the new medical environment. Specialized subject librarians can provide accurate, objective, and scientific library and information services for surgeons and help them understand the ever-increasing number of new issues in surgery. Therefore, the establishment of the subject librarian clinical service system and specialty service modes will play a guiding role in China's medical model and medical education in the new era. In this manner, librarians will increase their contribution to human health and socioeconomic development.

\section{Research status in China and abroad}

\subsection{Studies outside China}

The subject librarian first emerged outside China. Danton $^{6}$ noted that in Germany, the subject librarian has a long history dating back to the early 19th century and that the Germans were the first to conduct research on subject librarians. Crossly argued that the British subject librarian could be traced back much farther, to the Renaissance, when librarians at research universities were frequently authoritative experts on law, literature, or theology. ${ }^{6}$ At the beginning of the 20th century, several British universities began to introduce the subject librarian system, which became popular in the 1960s. However, following the Second World War, the research level of library science in the United States came to the forefront and has generally surpassed that of Europe. Currently, the overall research level in the United States ranks first worldwide. In this regard, the Columbia University library is representative. The university's strategic plan ${ }^{7}$ states that subject librarians must provide comprehensive advisory services and user guidance with respect to information resources (including subjectspecific resource information, common software, text analysis, and document management) for scientific research in various ways (e.g., electronic, face-to-face, formal, and informal). At present, Columbia's library is generally recognized as the university library with the most complete system of subject librarians in the United States.

There are several models for the establishment of librarian services in medical fields in countries outside China, e.g., comprehensive subject services, special subject services, and medical subject librarian services.

\subsubsection{Comprehensive subject librarian services}

(1) In collaboration with several libraries in the New England region, the Medical School of the University of Massachusetts has developed the New England Collaborative Data Management Curriculum (NECDMC) project. The University of Massachusetts Medical School Library has uploaded guidance courses on the Internet for the instruction of researchers and students. The courses include best-practices studies on the management of scientific data, for example, in clinical research, biomedical laboratories, engineering projects, and qualitative research in behavioral medicine. In addition, the library provides data management support services for biomedical disciplines in the following three areas: (1) scientific data management; (2) data management consulting; and (3) medical database resources. ${ }^{8}$

(2) Johns Hopkins University in Maryland is a wellknown US research university. Its embedded librarian service research is a leader among the world's medical libraries. Subject librarians from the library provide services to teachers and students of the School of Medicine, the School of Nursing, and the School of Public Health of Johns Hopkins University, ${ }^{2}$ and their studies in the related subject area are among the best. Founded in 1929, the Johns Hopkins Welch Medical Library is a branch of Johns Hopkins University Library. The medical library's embedded librarians account for one-fifth of the library's employees and provide services for 
faculty, students, and investigators of the School of Medicine, the School of Nursing, and the School of Public Health and for clinicians and staff of Johns Hopkins Hospital and the Kennedy Krieger Institute. Clinical librarians of the Welch Medical Library are requested to participate in clinical systematic reviews and conduct research on surgical effectiveness in the treatment process. ${ }^{9}$

\subsubsection{Special medical subject librarian services}

Librarians of the US National Institutes of Health (NIH) Library are integrated in many specialized clinical research teams and thus an integral part of such teams. ${ }^{10}$ For example, subject librarians are involved in the retina and genetics team of the National Eye Institute (NEI), whereas other librarians have long been involved in clinical data analyses at the Center for Information Technology (CIT) and the Mathematical and Statistical Computing Laboratory (MSCL). In collaboration with the Schools of Medicine and Public Health, the University of Washington Library dispatches subject librarians with specific knowledge on certain subjects to laboratories and computer laboratories in various departments to provide software support services to researchers for nucleic acid sequence analysis. ${ }^{11}$

\subsubsection{Medical subject librarian services}

The 2009 Strategic Plan of Yale Medical Library proposed a subject librarian service. ${ }^{12}$ The subject service goal was to embed subject librarians and information specialists in student education and to provide other support for student learning. ${ }^{13}$ Regarding individualized services and subject services, the new edition of the strategic plan (2009-2013) proposed integrating the library into teaching curricula to support diversified teaching methods to meet various learning needs as well as to study and provide personalized services based on user needs. The library has also introduced subject librarian services for other subjects. The clinical medical librarian program at the Yale Medical Library requires subject librarians to be integrated in medical services to promote the retrieval and use of information by clinicians. ${ }^{13}$ The Collection Development Program was implemented for specialized clinical departments. In the Personal Librarian Program, ${ }^{14}$ special subject librarians were appointed to be responsible for providing information advice and services to students, whereas the Liaison Librarians Program ${ }^{15}$ provides subject services for the entire medical school, including faculty and staff of basic medical research units. ${ }^{16}$ These programs have achieved good results, and the development of subject services in the library has become the leading force of Yale's innovative services.

Cambridge University released an evaluation report in 2010, ${ }^{16}$ in which an integrated system consisting of the library system, teachers, and the medical school was established as a new comprehensive subject librarian service model to support teaching and learning. In its 2010-2013 strategic framework, the Cambridge University Library used the model as a guide for its subject services and established leadership teams for teaching and learning services and the research and development of new technologies.

The subject librarian system in countries outside China has many advantages. However, it also displays several shortcomings. Among them, most medical libraries provide data services unilaterally, which involves the following inadequacies: (1) subject librarians lack knowledge or professional skills in the subject and (2) subject librarians often do not understand the details of scientific research projects. These problems are common among subject librarians who provide clinical services.

\subsection{Studies in China}

\subsubsection{Main issues}

According to the studies conducted in China, the main issues in modern clinical surgery are as follows. (1) Modern surgery is involved in an increasingly wider range of diseases and more disciplines. Similarly, the number of diseases that exclusively require surgical treatment is decreasing. Surgery plays a role in nearly all types of treatments, whereas the subdivisions of the discipline are becoming more specialized. (2) In the process of surgery's development, more interdisciplinary fields outside traditional medicine have emerged. Each time a new problem arises, the scope of surgical research expands and deepens. Thus, the surgeon's area of professional responsibility is increasingly specialized. However, the time and energy available to surgeons are limited. Thus, it is impossible for them to find and consolidate the clinical and scientific information they require.

These two major issues indicate that clinical medicine-oriented subject librarians are urgently required to specialize their expertise, so that they can provide support for evidence-based medicine and real-time clinical information service.

\subsubsection{Main service models}

The achievements of medical subject librarians in China are more limited than those of such librarians in other countries. Based on the research topic, the scope of the 
discipline can be divided into two categories as follows: surgery subject services and medical subject librarian services. The latter can be further divided into two subcategories as follows: the subject librarian services of medical school libraries (or the medical libraries of key universities) and the subject librarian services of hospital libraries. The classification is described in additional detail in the following four sections.

\section{(1) Surgery subject services}

As early as the Zhou dynasty (1046-771 BC), China established the world's first hospital and medical system. Zhou medical institutions included physicians, Shangshi, Xiashi, Fu (in charge of pharmacy), Shi (in charge of recordkeeping), and several types of apprentice. Other medical personnel were categorized into four categories as follows: Shiyi (in charge of diet and inventory), Jiyi (internal medicine), Yangyi (surgery), and veterinarians. This system represents the world's first division of medical services. ${ }^{17}$ Yangyi were the equivalent of today's surgeons.

Today, clinicians pay much attention to research models of evidence-based medicine in the field of medical information services. Evidence-based medicine is a research method based on the inversion of the burden of evidence. Accurate medical information is required so that an appropriate treatment method can be determined to address the problems faced by clinicians. ${ }^{18}$ Subject librarians can help doctors shift the burden of evidence with the relevant medical literature and information and help them determine the most appropriate treatment using evidence-based medicine.

In addition, from the perspective of bibliometrics, clinical surgery research is continuously being enriched. Research methods are continuously being updated, whereas interdisciplinarity is constantly increasing. Statistical analysis of key surgery journals for the recent 10 years indicates that the entire surgery literature is not being covered. Because of the large number of keywords and subkeywords, omissions are inevitable. As a result of a lack of training in novelty assessment, it is difficult for medical staff members to achieve complete coverage of the surgical literature when conducting clinical studies. Subject librarians can take advantage of their expertise to ensure full coverage and accuracy with respect to the requisite literature and help doctors obtain the most comprehensive and accurate information.

\section{(2) Medical subject librarian services}

University library's subject librarian services were initiated much later in China than in other countries. In
1998, Tsinghua University was the first in the mainland of China to implement the subject librarian system. ${ }^{19}$ The university has since been followed by libraries in major universities and research institutions, and the models and tools of subject services and subject librarians have become popular topics in library service research. ${ }^{20,21}$ After more than 10 years of practice and experiment, specialized subject librarian services have developed new service contents. However, clinical librarian services are in urgent need of further development.

In terms of the content of the service system, university libraries in China and abroad rarely vary. However, in terms of the width and depth of subject services, they vary dramatically. In China, institutions that provide subject librarian services are concentrated in medical university libraries, whereas hospital libraries only provide limited subject librarian services.

(3) Medical school library's subject librarian services

In China, the leading medical university libraries are Central South University Medical Library, Peking University Health Science Library, and the Medical Branch of Huazhong University of Science and Technology Library. These medical libraries possess sufficient collections of scientific literature and the ability to organize the information resources on a certain subject. Thus, they can provide solid subject information services while suggesting a direction for management and service innovations at comprehensive medical university libraries. ${ }^{22}$

Central South University Library offers advanced subject services at the information specialist level of "embedded informationist". The facility's medical librarians have librarianship backgrounds and are familiar with various literature resources of a certain clinical subject. Thus, they can provide targeted information services for selected teaching and research objectives. The embedded librarians are familiar with and in certain cases proficient in one subject or several subjects. Thus, they can provide targeted advisory services for evidence-based medicine.

In addition, several medical university libraries provide a liaison librarian service. For example, the service direction of Peking University Health Science Library is information research, fixed-topic information service, literature search, and novelty assessment. Huazhong University of Science and Technology Library Medical Branch offers subject librarian services that primarily provide quality literature-research services, strengthen the links between libraries and colleges (i.e., academic departments), and establish a smooth flow of information 
to meet the in-depth needs of the faculty for teaching and research resources.

\section{(4) Hospital library's subject librarian services}

Zhang, ${ }^{22}$ a neurosurgery expert, argued that in the big data era medical research has the following three main characteristics: (1) the mining, collection, collation, and use of clinical resources; (2) large samplesize, multi-center clinical studies; and (3) the collation, use, and investigation of clinical information-dependent biomedical resources. Therefore, hospital subject librarians must collect appropriate big data resources and enrich relevant collection resources according to the needs of physicians. In addition, they must assist physicians in collecting and integrating the clinical data of the hospital to establish a small database with specialty characteristics while gradually expanding the number of data.

Before providing hospital librarian services, subject librarians should conduct surveys on the demand for such services. Additionally, they should learn the main research directions of their physicians through discussion and by attending departmental seminars. They should also seek to understand the information behavior, research methods, and the frequency and preference of library resource use of their physicians.

\subsection{Comparison of research fields in China and abroad}

Generally, regarding the specific clinical fields of clinical librarian services, studies in countries outside China have contributed to the establishment of mature clinical subject librarian systems focused on the outcome of subject services, clinical evidencebased medicine, and comprehensive clinical consultation services. In China, the focus has been on the system and the service methods of subject librarians. The research largely remains in the theoretical stage, and stakeholders have been unable to establish a mature subject librarian system focused on clinical medicine.

According to the most advanced studies, ${ }^{23}$ individuals with an aptitude for integration who are proficient in biomedicine and clinical information science are the best candidates to serve as clinical medicine subject librarians. However, current circumstances leave little room for optimism, and many hospital librarians are part-time physicians. Staffing limitations make it difficult to form appropriate research teams that are capable of mining network resources and databases. Medical university libraries enjoy important advantages with respect to talent and information resources and thus an advantage with respect to establishing subject librarian services. Therefore, they represent the first choice in the search for individuals capable of integrating in clinical teaching and research and contributing to research and clinical work at hospitals.

\section{Practical implications}

Medical university libraries typically possess sufficient hardcopy and electronic resources. Thus, clinical subject librarians at such facilities are in a position to share the rich medical resources of these medical libraries with their affiliated medical institutions, provincial or municipal medical institutions, community hospitals, and other relevant medical departments. For example, these subject librarians could contribute specialized information resources of their university medical libraries that would support various aspects of surgery, such as clinical teaching, clinical surgery, clinical nursing, and clinical research. This new type of practical model, in which university libraries serve clinical surgery, can serve as a template and practice reference for the development of library services at other medical universities.

\subsection{Medical model perspective}

Clinical subject librarian services can contribute to overcoming a deficiency in medical university library services regarding surgery and the theory of human health. The focus of medicine is human beings. However, human individuals vary so widely that the manifestations of the same disease may be different. With the rapid growth of big data, the number of inferior data also increases. In addition, factual and decision errors caused by data-quality problems have had adverse consequences worldwide. Against the medical big data background, subject librarians must learn to search for patterns and small data appropriate to given individuals. In this manner, they can help physicians avoid poor data and make good use of good data to achieve precise, personalized medical treatment, and thus support the healthy development of clinical research and treatment.

\subsection{Bibliometric perspective}

Clinical subject librarian services will support bibliometric studies on key clinical surgery research and comparative research by medical university libraries. Surgery and its scientific research require a sufficient reserve 
of research literature, and the required literature must be available in real time. The establishment of key clinical surgical literature databases would be conducive to the development of clinical evidence-based medicine. Therefore, it is of substantial importance to discern the hardcopy and electronic resources that surgical clinicians require and to establish a collection of the relevant literature.

\section{Conclusions}

In foreign medical librarian services, when performing comprehensive data services for research teams, subject librarians must not only understand a project's research process but also establish close contact with researchers to become useful collaborators in that

\section{References}

1. Li $Y Z$, Zhang $X Y$, Zhou J, et al. New recognition of knowledge services in the medical field and the embedded librarian. Libr Work Study. 2016;1:112 114 (in Chinese).

2. Li L. Case study on the implications of the medical library embedded librarian service: John Hopkins University Welch Medical Library. Res Libr Sci. 2013;17:95-98 (in Chinese).

3. Duan ZG, Xu DQ. Collaboration relationships of Nobel Prize winners in physiology or medicine. Stud Philos Sci Tech. 2015;2:92-96 (in Chinese).

4. Lu XY, Xian FH, Jiang JM, et al. Discussion on improving the training plan of the Level 2 disciplines of the 7-year clinical medicine major. $J$ Capital Univ Med Sci. 170-173 (in Chinese).

5. National Library Editorial Board of the Chinese Library Classification. Chinese Library Classification. Beijing: National Library Press; 2010 (in Chinese).

6. Danton JP. Selection and collections: a comparison of German and American university libraries. New York: Columbia University Press; 1963.

7. Columbia University. Columbia university libraries information services strategic plan 2010-2013. http://www.columbia.edu/cu/web/img/assets/6675/ CULIS_Strategic_Plan_2010-2013.pdf. Accessed October 21, 2011.

8. Affiliated Libraries|Becker Medical Library. https:// becker.wustl.edu/about/affiliated-libraries\#family. Accessed December 13, 2013 (in Chinese).

9. Visitor Access Policy-Mayo Clinic Libraries-Mayo Clinic. http://www. mayo.edu/library/about/visitoraccess-policy. Accessed November 1, 2013. process. In such collaboration, subject librarians should promptly ascertain their own deficiencies and acquire the lacking knowledge. On the one hand, they should investigate the research environment of clinical surgery to expand their understanding of the entire workflow management of medical research. On the other hand, the collaboration between subject librarians and clinicians subtly affects researchers' data management awareness and data management skills. In addition, it promotes the progress of the library's data services by providing a model and practical guidance for medical universities in establishing clinical surgery services.

\section{Conflicts of interest}

All contributing authors declare no conflicts of interest.
10. Clark C. The "embedded librarian": NIH informationists become team players. NIH Catal. 2005;31:14-15.

11. Yanfitz S, Ketchell DS. A library-based bioinformatics services program. Bull Med Libr Assoc. 2000;88:36-48.

12. Yale Medical Library. Annual Report 2008-2009. http://www.med.yale.edu/library/about/annualreport09.pdf. Accessed October 21, 2011.

13. Kurup V, Hersey D. The perioperative librarian: luxury or necessity? Curr Opin Anesthesiol. 2007;20:585-589.

14. Larson J. http://www.library.yale.edu/rsc/subjspec/ jkl.html. Accessed November 4, 2009.

15. Training and Certification. https://medapps 13 . med.yale.edu/tms/tms_enrollments.categories?p_ own_cd $=$ LIB\&p_std_id $=$. Accessed November 4, 2009.

16. Cambridge University Library. Annual report for the year 2009-2010. http://www.lib.cam.ac.uk/About/ annual_report_2009-10.pdf. Accessed June 5, 2015.

17. Zhang H. "A complete collection of Yangyi": characteristics of sores and signs. Anhui Univ Chin Med. 2011;30:7-8 (in Chinese).

18. Sun YP. Medical library consulting services for evidence-based decision-making. Libr Work Study. 2006; 4: 47-48 (in Chinese).

19. Tsinghua University Library. http://www.lib.tsinghua. edu.Cn/service/sub_librarian.html. Accessed May 11, 2011 (in Chinese).

20. Chu JL. Role of new generation subject librarians. Libr Theory Pract. 2007;3:1-3 (in Chinese). 
21. Chu JL, Zhang DR. Subject librarian 2.0 and subject services. Libr Inform Serv. 2008;52:6-10, 68 (in Chinese).

22. Shen HJ, Zhang ZG, Guo SY. Construction of the university institutional repository using
Web 2.0. J Modern Info. 2013;3:49-51, 55 (in Chinese).

23. Cheng $\mathrm{H}$, Li HJ. Subject librarian services in medical colleges. J Dis Monitor Control. 2013;7:221-222 (in Chinese).

How to cite this article: He Q. Clinical surgery-oriented subject librarian services in medical colleges and schools. Front Nurs. 2018; 4: 257-264. https://doi.org/10.1515/fon-2018-0034. 